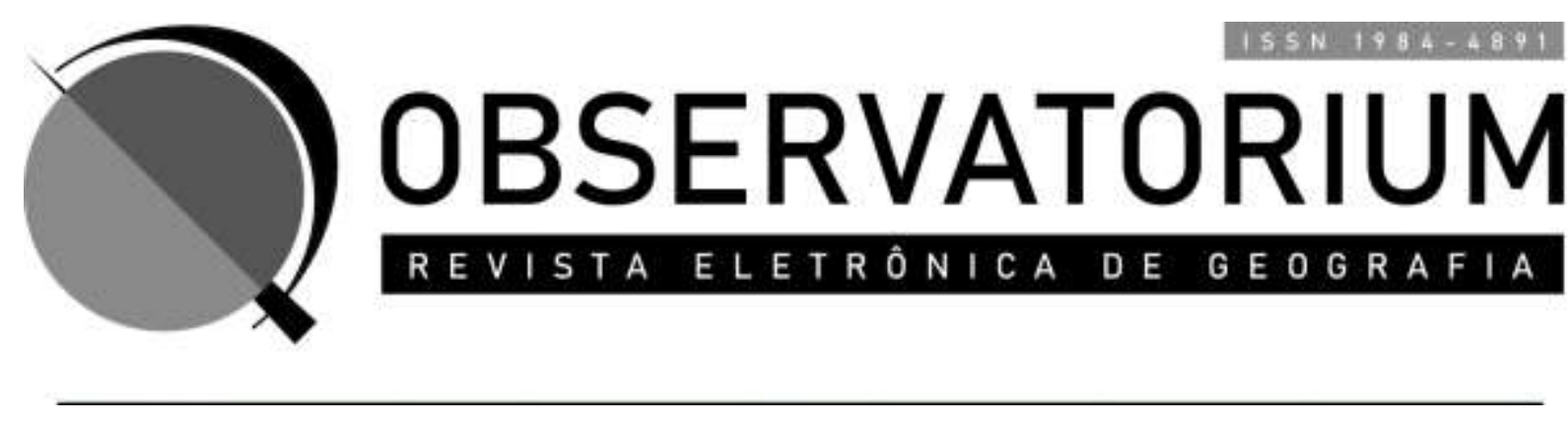

\title{
RATZEL E A INSTITUCIONALIZAÇÃO DA GEOGRAFIA MODERNA'
}

\author{
RATZEL AND THE INSTITUTIONALIZATION OF MODERN GEOGRAPHY
}

Rita de Cassia Martins de Souza²

\begin{abstract}
RESUMO
Entre os propositores da disciplina Geografia, Ratzel tem lugar reservado entre os pioneiros geógrafos. Suas contribuições são de ordem temática e teórico-metodológica, numa proposta multidisciplinar trazendo luz à fusão e ao deslocamento dos homens na superfície do planeta, aproximando distintas disciplinas em formação no século XIX como a etnologia, a ecologia, a história, sociologia e a própria geografia. Ao lado de sua decisiva participação quanto à sistematização da Geografia, Ratzel desempenhou importante papel na sua institucionalização. Foi professor na Politécnica de Munique e na Universidade de Leipzig onde introduziu a sua Antropogeografia. O autor foi responsável também por propor a divisão da disciplina em 3 subcampos: Biogeografia; Antropogeografia; Geografia Física que ainda hoje marcam o currículo dos cursos de Geografia no mundo todo.
\end{abstract}

PALAVRAS-CHAVE: Geografia; Institucionalização; Universidades

\begin{abstract}
Among the pioneering geographers proposing the discipline of Geography, Ratzel has a reserved place. His contributions are of a thematic and theoretical-methodological order, in a multidisciplinary proposal on the understanding of the displacement of men on the planet's surface, bringing together different disciplines in formation in the 19th century, such as ethnology, ecology, history, sociology and geography. With a decisive participation in the systematization of Geography, Ratzel also played an important role in institutionalization. He was a professor at the Polytechnic of Munich and at the University of Leipzig where he introduced his Anthropogeography. The author was also

\footnotetext{
${ }^{1}$ Palestra apresentada em 29/05/2019 em evento comemorativo do Dia do Geógrafo organizada pelo PET Geografia-UFU. Este trabalho faz parte do desenvolvimento da pesquisa financiada pela FAPEMIG sob o título: "A geografia produzida em Minas Gerais: os cursos de Geografia na UFMG, UFJF, UNIMONTES, UNIFAL e UFU e seu papel na estruturação do território mineiro”. Processo: APQ-01851-15

2 Docente de Graduação e Pós -Graduação do Instituto de Geografia da Universidade Federal de Uberlândia - UFU. E-mail: ritacmsou@gmail.com
} 
responsible for proposing the division of geography into 3 subfields: Biogeography; Anthropogeography; Physical Geography that still mark the curriculum of Geography courses around the world today.

KEYWORDS: Geography; Institutionalization; Universities

\section{INTRODUÇÃO}

A grande contribuição que Friedrich Ratzel (1844-1904) ofereceu à sistematização da Geografia é reconhecida e sempre discutida entre os estudiosos da fundação da Geografia Moderna. Esse viajante naturalista prussiano representou papel fundamental para a organização dos pressupostos básicos da Geografia no final do século XIX, dedicando-se de forma pioneira, ao lado de Carl Ritter, às formulações de estudos geográficos dedicados à discussão dos problemas humanos. O projeto teórico proposto por Ratzel era de ordem interdisciplinar fazendo aproximarem-se distintas disciplinas em formação à época como a etnologia, a ecologia, a história e a própria geografia, trazendo luz à fusão e ao deslocamento dos homens na superfície do planeta. Entretanto, não menos importante foi o papel que esse geógrafo desempenhou na institucionalização da disciplina, embora não se possa dissociar um evento do outro: sistematização e institucionalização são processos paralelos e indissociáveis.

No entendimento sobre a institucionalização da Geografia no século XIX devese ponderar sobre a importância das viagens dos naturalistas e seus respectivos relatórios. Para que a disciplina científica Geografia aparecesse como tal no final desse século foi necessária a circulação do discurso geográfico por várias instituições antes que pela universidade propriamente. Foi a viagem aos Estados Unidos da América entre 1873 e 1875 para o jornal Konisch Zeitung que permitiu a Ratzel, após o tratamento dos dados levantados, a elaboração da "tese" sobre a migração chinesa que lhe rendeu o cargo de professor na Universidade de Munique.

Deve-se ter em conta que a institucionalização da disciplina se deu em vários espaços institucionais antes que na Academia. Como já assinalado por outros estudiosos deve-se remeter sempre às Sociedades de Geografia, aos Institutos Histórico e Geográficos, às escolas de ensino básico, mas também às revistas periódicas, aos jornais, aos relatórios de viagem, como espaços institucionais de divulgação de teses e de trabalhos de caráter científico em geral. Essa consideração 
amplia o campo de observação e de atenção para a compreensão mais justa da formação da disciplina antes da consolidação do sistema universitário, acadêmico em que oficialmente as mesmas aparecem contemporaneamente.

As viagens de Ratzel foram, assim como no caso de grande parte dos naturalistas no século XIX como Alexander Von Humboldt, por exemplo, decisivas para a coleta do material que deu origem às suas teorias principais, cuja primordial preocupação sempre foi a associação entre os aspectos da natureza em sua interação com o desenvolvimento humano. Tal associação permitiu, sobretudo o aparecimento de uma disciplina como a Geografia que desde então se propôs multidisciplinar o que lhe rendeu adeptos e adversários fervorosos. A multidisciplinariedade, segundo alguns autores, foi mesmo uma estratégia da comunidade de geógrafos à época no sentido de garantir a institucionalização da disciplina em meio ao surgimento de várias outras, sobretudo as ciências humanas no século XIX.

Parece interessante considerar que ao tempo que a sistematização dos temas e do aporte teórico se faz por um ferramental internalizado à cada ciência, a compreensão de sua institucionalização requer fundamentalmente que se compreenda os contextos que permitirão sua consagração, as negociações, as tramas envolvidas na eleição dos envolvidos etc. Inclusive os rumos da própria sistematização passam pela política que permitirá certas generalizações ou certas temáticas se desenvolveram ou não em determinados ambientes institucionais (LATOUR, 2000).

Este texto sobre Ratzel foi produzido para o Ciclo de Palestras: Clássicos da Geografia. Humboldt \& Ratzel, organizado pelo Programa de Educação Tutorial PET-Geografia da Universidade Federal de Uberlândia, realizado no dia 29 de maio de 2019. Foi construído tendo em vista a necessidade de manter viva a história da Geografia, apresentando-a aos iniciantes no curso, mas também aos demais interessados da comunidade acadêmica. Teve por objetivo também direcionar a reflexão para o contexto atual dos cursos de Geografia e nesse sentido, procurou-se fazer uma reflexão sobre o desenvolvimento do pensamento científico por dentro das universidades tendo em vista que Ratzel não somente contribuiu para a sistematização da Geografia enquanto campo científico, mas foi decisivo para colocar a Geografia no meio acadêmico. 


\section{RATZEL E A CONSAGRAÇÃO DA GEOGRAFIA COMO DISCIPLINA CIENTÍFICO-ACADÊMICA: O CONCEITO DE TERRITÓRIO E SUAS POLÊMICAS ACADÊMICAS E POLÍTICAS}

O Século XIX foi marcado por intensos embates na Europa em virtude das grandes transformações em processo desde o século anterior com a Revolução Industrial, a Revolução Francesa e a Revolução Científica. Evidentemente, as três revoluções mencionadas estavam absolutamente integradas a um único processo, qual seja o da instalação do modo de produção capitalista em sua forma industrial assalariada. Parte-se do pressuposto que as transformações da base material não ocorrem sem grandes transformações na base do pensamento. Nesse sentido, a compreensão do desenvolvimento do pensamento de forma geral e do pensamento geográfico, em particular, é essencial.

A inserção tardia da Alemanha no processo de formação dos Estados Nacionais europeus, como é sabido, trouxe uma série de consequências que se desdobraram interna e externamente. A centralização política demandou um discurso legitimador da mesma que encontrou, por volta da segunda metade do século XIX, em meio às disputas por recursos como o carvão da Alsácia e da Lorena (Fig.1), um forte impulso para a Geografia e sua institucionalização. Os pressupostos já vinham se construindo em termos de um conhecimento organizado, cujo conceito de paisagem formulado por Alexander Von Humboldt foi decisivo, além disso, as formulações de Carl Ritter associadas à paisagem, trouxeram um elemento essencial qual seja o da íntima relação entre os grupos humanos culturalmente organizados e a base natural de sua sustentação. As relações homem-meio aparecem casadas às preocupações estéticas de Humboldt na formulação do conceito paisagem apresentando, finalmente, a formulação básica que sustentará a Geografia científica à época. 


\section{Fig.1 - Alsácia e Lorena: Império Alemão Século XIX}

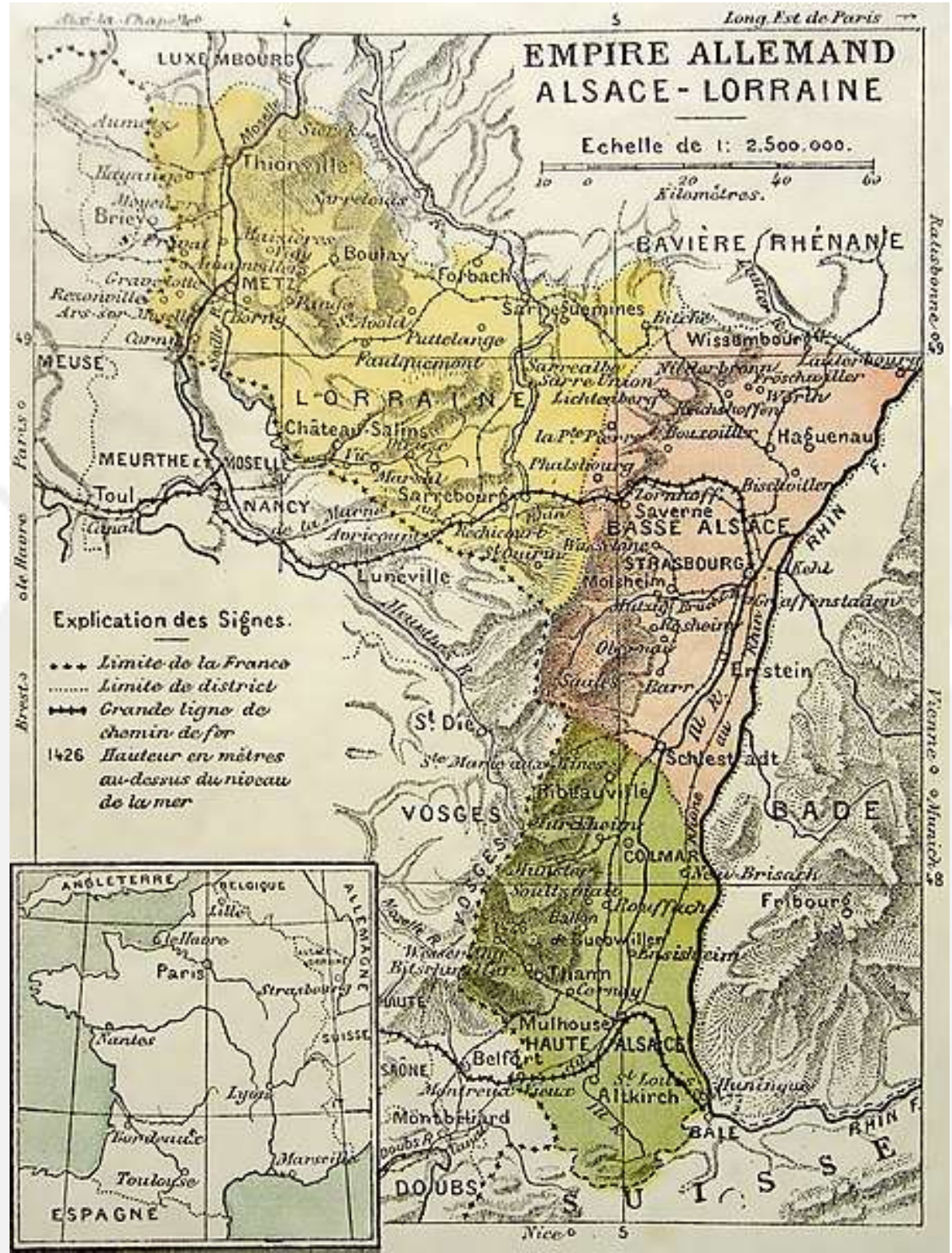

Fonte: Diário dos Extremos, 2013

As influências dessas ideias encontraram desdobramentos no pensamento de Friedrich Ratzel que seguiu a linha condutora da criação de uma nova disciplina conforme proposto por Ritter. Embora não partilhasse dos ideais românticos dos dois primeiros e, portanto, rejeitasse terminantemente os subjetivismos, este geógrafo acabou compondo uma proposição que aliava o conhecimento da natureza ao conhecimento das relações humanas através do conceito de território.

Evidentemente, o momento não poderia ter acolhido melhor as ideias ratzelianas uma vez que ferviam a esse tempo as disputas pela unificação germânica. O discurso acerca de um território em que os grupos humanos identificados 
culturalmente pela língua e pelos costumes que, segundo Ratzel, se encontravam em perfeita sintonia com o seu "solo" ou a sua paisagem, favoreceu o discurso da unificação. Também serviu fortemente para a retomada da Alsácia e da Lorena, regiões de língua germânica anexadas pelos franceses durante o reinado de Louis XIV (16381715). Não é demais lembrar que a presença de carvão nessa região era de crucial importância para a industrialização da Prússia e por extensão para toda a Alemanha unificada (Fig.2).

Fig. 2 - Alsácia e Lorena: Fases da Unificação (1864-1871)

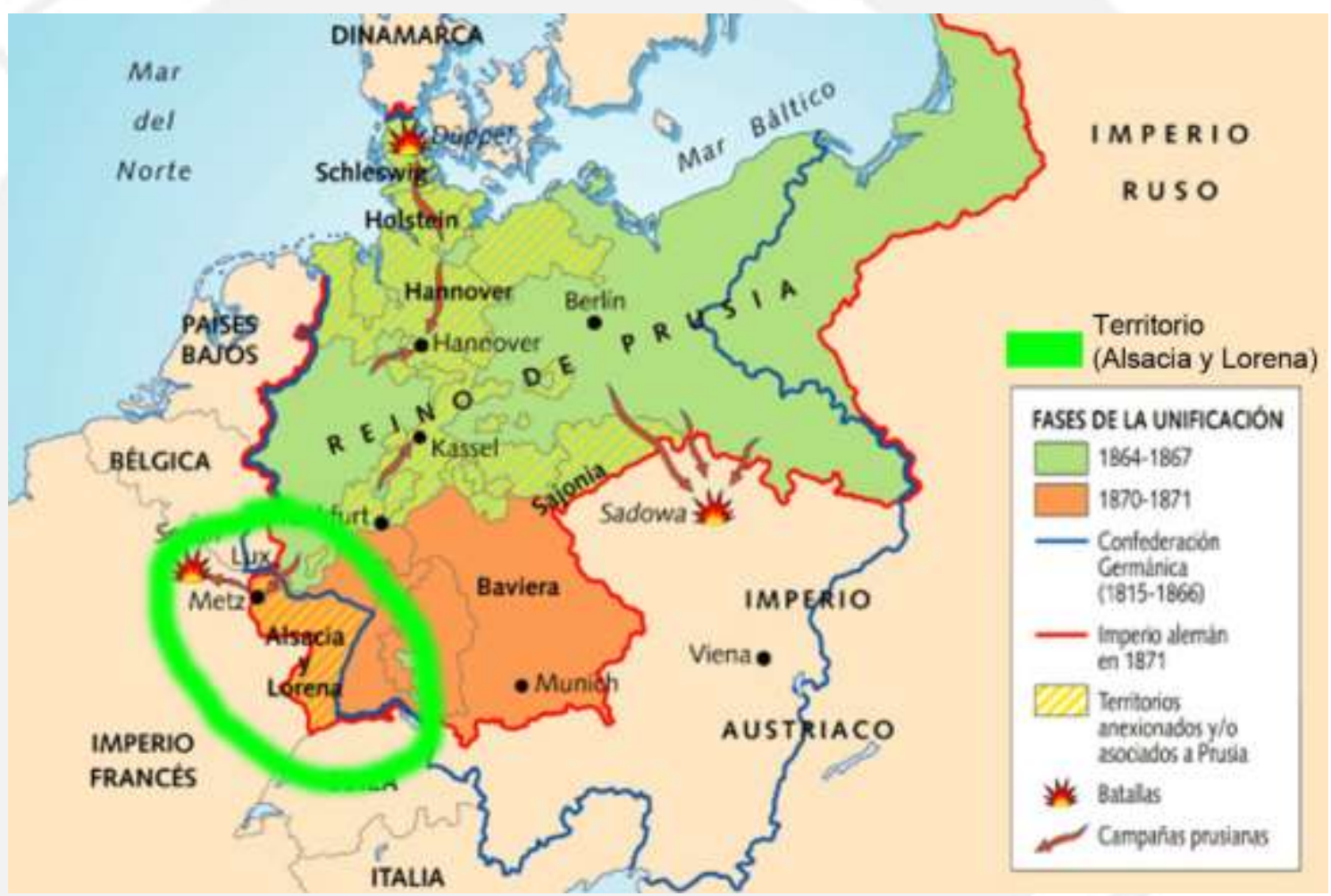

Fonte: Diário dos Extremos, 2013

Segundo Moraes (1990, p. 9):

Essa disciplina teria por campo material a Terra, abarcando, porém, a análise do homem, posto como um "ser terrestre". Na medida em que a história humana, segundo ele, integra-se plenamente com a história do planeta, a geografia poderia ser, a um só tempo, uma ciência humana e da Terra - um domínio de contato entre fenômenos naturais e sociais. Esse enunciado aparecerá como um dos mais recorrentes nas posteriores propostas de tal disciplina.

Mediante o exposto ainda que tão brevemente, já se pode perceber a profunda conexão entre o desenvolvimento da disciplina científica Geografia e o contexto que lhe subjaz. A íntima ligação entre o conhecimento geográfico e as necessidades do 
Estado Moderno (entranhados, como não poderia deixar de ser no espírito do capitalismo industrial e da classe burguesa) instigam a organização dessas ideias que recebem o apoio estatal, por exemplo na introdução das aulas de Geografia no ensino básico juntamente ao de História ou mesmo através do apoio e forte interação com as Sociedades Geográficas, conforme tão bem tratado por Capel (1977), sem contar ainda a Geografia que se foi estruturando nas Escolas Maiores ou Militares, conforme abordou o texto clássico de Yves Lacoste (2020 [1977]). A parceria acaba fundamentando o sentimento de Pátria tão forte desde o fim do século XVIII na Europa e, por desdobramento, em todos os lugares onde o capitalismo se deu e demandou a figura centralizadora do Estado, independentemente do regime de governo adotado. Portanto, a elaboração do conceito de território, embora tenha sido apresentado por Ratzel nos moldes do mecanicismo positivista, negando todo grau de subjetividade herdado dos pioneiros "geógrafos", esteve desde sempre carregado de intencionalidades políticas.

Entre as principais críticas ao território e ao "espaço vital/lebensraum" de Ratzel, formuladas pelos franceses encontra-se a determinação das condições do ambiente sobre o homem. Lucien Febvre, enquanto historiador e parceiro de Vidal de La Blache, chamou a teoria ratzeliana de "determinismo ambiental" com um caráter essencialmente pejorativo, enquanto engrandecia as formulações lablachianas de "possibilistas", como que numa inversão da ordem de forças. O que não se pode esquecer são duas coisas: em primeiro lugar a inversão não retira o caráter positivista da busca da causa e efeito, por si somente; e em segundo lugar, claramente há uma disputa política nacionalista pela "melhor" colocação da geografia no rol das disciplinas científicas. Não é sem razão, portanto, que a reação dos franceses, experimentando também o desenvolvimento do conhecimento geográfico, vai rechaçar a proposição do território como categoria ou conceito científico atribuindo a ele um sentido ideologizado, pois, segundo eles, comprometido com os interesses do Estado alemão.

No jogo das críticas e dos elogios que não se perca de vista em primeiro lugar a necessidade de contextualização a fim de se entender a importância e o peso das formulações ratzelianas. $\mathrm{O}$ chamado determinismo ambiental faz parte, na verdade, de um contexto em que teorias racistas se apresentavam no sentido de compreender as diferenças entre as diversas sociedades e que a proposição de Ratzel não se alinha às mesmas, embora sendo também evolucionista como já apontado por MACHADO 
(1995). Não sem razão a teoria mesológica desse geógrafo influenciou outros nomes da ciência importantes à época.

Entre os estudiosos da obra de Ratzel é inequívoca a afirmação sobre a relativização que o autor faz em torno da determinação das condições ambientais sobre as ações dos homens, negando o determinismo estreito de um Montesquieu, por exemplo. Além disso, há de se considerar que a construção cultural é extremamente importante em suas formulações levando-o à proposição do grau de civilização e, por outro lado ainda, a condição de interação profunda dos homens ao lugar que os ligam à natureza como "sua", como seu "solo", conforme desenvolvido em "Solo, a sociedade e o Estado" (1898), de sua autoria.

Vários autores já apontaram esses equívocos que, entretanto, persistem nas obras de vulgarização. Ratzel foi um crítico do determinismo simplista, o qual em sua opinião prestou um desserviço à geografia ao tentar explicar de imediato e por uma via especulativa, sem base empírica - a complexa questão das influências das condições naturais sobre a humanidade. Ele chegou a tecer críticas contundentes à idéia "obscura" de ser o homem "um produto do meio". Também a idéia de predestinação dos lugares, elaborada por Ritter, foi alvo de seu ataque, ao qual não escaparam as colocações deterministas de Montesquieu. Desse modo, não há como colocar Ratzel no mesmo rol desses autores e mesmo de alguns de seus discípulos, como, por exemplo, Ellen Semple, efetivamente uma autora determinista. A sua visão do condicionamento dos elementos ambientais sobre o homem e a sociedade é bem mais rica e mediatizada. (MORAES, 1990, p.10)

\section{RATZEL E A CONSOLIDAÇÃO DA GEOGRAFIA ACADÊMICA: O PAPEL DA UNIVERSIDADE COMO UMA DAS INSTITUIÇÕES DO SABER GEOGRÁFICO}

Moraes (1990) atribui a Ratzel o decisivo papel de consolidação da Geografia no meio acadêmico científico através da adoção do método positivista que se colocava na segunda metade do século XIX como preponderante também para as ciências humanas no seu processo de institucionalização.

É interessante notar os mecanismos e estratégias utilizados pela comunidade de geógrafos em formação à época e, em princípio, pode-se dizer que a proposição de Ratzel é uma das melhores expressões deles. A associação entre fenômenos considerados de diferentes ordens e cujos métodos de compreensão não se cruzariam como aqueles decorrentes da natureza e os outros decorrentes das relações entre os homens, encontrou no conhecimento geográfico proposto por Ratzel uma possibilidade de aproximação. 
Em Humboldt e Ritter, dado o subjetivismo inerente às tendências neokantistas ou românticas, a síntese era princípio para compreensão de todas as coisas e assim, a interligação dos fenômenos da natureza às relações humanas são inerentes à própria visão de mundo (conforme concepção de Lucien Goldman, 1967) ou método de interpretação (ver Moraes, 1999). Entretanto, para o positivismo, em que a análise predomina, os temas e os fenômenos não compõem um todo indissolúvel para o conhecimento e, portanto, é impossível falar de uma ciência "única".

Segundo as palavras de Comte:

Conforme profunda convicção pessoal, considero essas tentativas de explicação universal de todos os fenômenos por uma única lei como eminentemente quiméricas, mesmo quando são tentadas pelas mais competentes inteligências... não há uma unidade indispensável (...) senão a unidade de método, a qual pode e deve evidentemente existir e já se encontra, na maior parte, estabelecida (...) Tendendo a diminuir, à maior quantidade possível, o número das leis gerais necessárias para a explicação positiva dos fenômenos naturais, o que é, com efeito, a meta filosófica da ciência, consideraremos, entretanto, como temerário aspirar algum dia, ainda que para um futuro muito afastado, a reduzilas rigorosamente a uma só. (Comte apud BRANDÃO, 2011, p. 89).

No positivismo a unidade do conhecimento se dá pelo método, portanto. Segundo a classificação de Comte, seu propositor, a Matemática, como conhecimento mais geral e básico de todos aparece como a "primeira ciência"; a segunda ciência é a Física celeste (Astronomia), dividida em Física propriamente dita (terceira ciência) e Química (quarta ciência). A quinta ciência corresponde à Fisiologia (Biologia) e a sexta à Física Social (Sociologia). Todas as seis ciências são ordenadas hierarquicamente segundo os princípios positivos da natureza. Ou seja, o método de interpretação e o de investigação dos fenômenos seguem os princípios básicos da matemática e da física de modo que também a sociologia deve se pautar no conhecimento positivo.

A necessidade da sociologia torna-se óbvia uma vez que seria impossível estudar a espécie humana, partindo-se apenas de um estudo do indivíduo, fornecido pela fisiologia ou biologia. A sociologia parte desse estudo, pois funda-se nele, mas vai além. São essas duas ciências as últimas da classificação comteana: a biologia em quinto lugar e a sociologia em sexto e último. É, portanto, a sociologia a mais particular de todas as ciências. Os fenômenos por ela estudados são os mais complicados, os mais particulares, os mais concretos e também, no compreender de Comte, os mais interessantes para o homem. Ela é o fim a ser alcançado pela filosofia positiva, rumo à reestruturação da sociedade. (BRANDÃO, 2011, p.88)

Como se pode perceber a Geografia não tem enquadramento na classificação das ciências de Comte ou mesmo de Stuart Mill, pois encontra-se a meio termo. A 
proposição de Ratzel oferece uma possibilidade concreta por via do método e do temário para a legitimação da Geografia. O temário dividido entre conhecimentos de ordem física, biológica e humana resolvem-se no efeito estético da interação entre homens e a própria natureza. O conceito de paisagem de Humboldt, formulado sob a influência romântica (BARBOSA, 2011), por exemplo, ganha novo sentido.

A ligação de Ratzel com o positivismo de Comte é perceptível na forma como ele se esforça para encontrar a relação de causa e efeito nas interações entre os homens e o ambiente. Talvez devêssemos considerar que um dos maiores desafios era justamente encontrar a possibilidade da ordem, tal qual se encontra para as condições naturais, não nos seres humanos enquanto indivíduos, mas acima de tudo, nos homens organizados em grupos culturalmente estruturados. A grande dificuldade de Auguste Comte e Stuart Mill em organizar o corpo do conhecimento de forma estruturada e hierárquica apresenta-se também para Ratzel na medida que, partilhando das mesmas concepções materialistas, objetivistas dos dois filósofos, envolve-se nas mesmas armadilhas. Veja-se como o geógrafo responde à Doutrina da Necessidade3:

Porém, como sempre ocorre no desenvolvimento dos problemas científicos, nem tudo é governado por leis de necessidade; frequentemente, a casual concomitância de vários fenômenos históricos intervém também e exerce sua influência. Não foram estes os problemas que a geografia apontou em primeiro lugar, pois já desde os tempos antigos a filosofia se vinha aproximando deles. Na verdade, a esses problemas não pode permanecer estranho o pensador que investigue a sorte e o futuro da humanidade. Embora se observe, ao longo da evolução dos conceitos acerca das relações entre a natureza e a história, que as obras tanto de uma quanto de outra se tornam plenamente manifestas a qualquer ponto de vista, perceber as influências que a primeira exerce sobre a segunda é, ao contrário, algo extremamente difícil, tanto que se pode encontrar a esse respeito muitos conceitos prematuros e arriscados, que permaneceram, por isso, ineficazes e esquecidos, de modo que o que vemos sempre é o estudo ser retomado do início. Nos filósofos, nos historiadores, nos geógrafos da Antiguidade, encontramos uma verdadeira riqueza de conceitos antropogeográficos, o que surpreende duplamente, se se considera quanto eram limitados o horizonte geográfico e o conhecimento etnográfico e histórico daqueles tempos. Já em Hipócrates encontram-se excelentes observações sobre a influência que o clima exerce na vida dos povos; e em Estrabão, onde ele trata dos continentes e dos lugares singulares, encontram-se alguns conceitos

\footnotetext{
3 "Corretamente concebida, a doutrina da Necessidade Filosófica é simplesmente esta: sendo dados os motivos presentes à mente de um indivíduo e sendo dado, igualmente, o caráter e a disposição do indivíduo, a maneira pela qual ele irá agir pode ser inferida infalivelmente; se conhecêssemos completamente a pessoa e todos os induzimentos que atuam sobre ela, nós poderíamos predizer sua conduta com a mesma certeza com que podemos predizer qualquer evento físico". (J.S. MILL. A lógica das ciências morais)
} 
que os nossos manuais de geografia retomaram há apenas alguns decênios; e a necessidade que ele expressa de considerar a conformação diversa dos territórios como preordenada com base em um princípio racional é precisamente o conceito fundamental de Karl Ritter. (RATZEL, 1914 in: MORAES, 1990, p.33). [grifos meus]

Parece certo que Ratzel, concordando com a premissa positivista, afirma que é possível e necessário encontrar a causalidade e as leis invariáveis dos fenômenos naturais também para as relações humanas. E sua resposta não poderia ser mais conveniente à Geografia em sistematização e em busca do seu reconhecimento na segunda metade do XIX em meio às demais comunidades científicas. Tal reconhecimento passava sem dúvida pela afirmação de sua condição de disciplina científico acadêmica. E a proposição de uma natureza que se impõe pelos recursos disponíveis ou não, apresenta-se aos agrupamentos humanos como um desafio. Encontrar o nexo causal do grau de civilização de certos grupos em relação à natureza que os envolve torna-se um tema multidisciplinar na proposta ratzeliana conferindo legitimidade à Geografia no meio universitário da época.

Vale lembrar que a universidade europeia experimentou transformações profundas desde o século XVIII acompanhando o desenvolvimento dos processos mais amplos em curso. A Revolução Científica teve papel decisivo nessas transformações que se desdobraram no século XIX numa verdadeira Revolução Universitária como colocam Barreto; Filgueiras (2007). Desde esse momento a pesquisa calcada no cientificismo passa a ser atividade primordial por dentro das universidades. $\mathrm{O}$ cientificismo sustentado pelo método positivo do qual Comte é reconhecidamente fundador e sistematizador uma vez que sua classificação das ciências teve forte influência sobre as transformações profundas sofridas. Vale reforçar ainda que o século XIX configura-se como um período de intensas transformações e onde se expressam as maiores polêmicas advindas da "nova" sociedade capitalista assalariada que passa a dominar as regras do mundo social.

A convulsão desse momento é reconhecida nos debates e embates entre os grandes pensadores desse período e não é sem razão que entre as proposições feitas por estes salta aos olhos a preocupação de propor uma nova organização da vida humana. Nos positivistas a "ordem" se torna símbolo de uma sociedade ordeira, civilizada e progressista. A publicação de o Plano de Trabalho Científico Necessário para Organizar a Sociedade, em 1822, por Comte é bem representativo da forma como o positivismo era pensado como estruturador da vida e do pensamento em sociedade 
e, por desdobramento, a organização da universidade moderna deveria responder a essas necessidades tão prementes.

Ratzel participa da institucionalização da Geografia inicialmente na Politécnica de Munique, 1873, e depois, em 1883, na Universidade de Leipzig, quando, segundo Moraes, a publicação de sua obra Antropogeografia o consagrou definitivamente na academia.

A publicação desse livro em 1882 consagra seu autor no ambiente acadêmico alemão. Tanto que no ano seguinte Ratzel transfere-se para a Universidade de Leipzig, onde passa a ocupar a cátedra de geografia, substituindo Richthofen na cadeira que antes havia sido de Peschel. Ali ele vai desenvolver uma intensa atividade. Dirige a Sociedade de Geografia de Leipzig, onde orienta numerosos trabalhos. Edita a "Biblioteca de Manuais Geográficos", que publica, entre outras obras famosas, a Climatologia de Hann e a Morfologia de Penck. É coordenador do Comitê Central para o Estudo da Geografia da Alemanha, organismo estatal interuniversitário dedicado a levantamentos regionais monográficos. (MORAES, 1990, P.18).

Por esse relato já se percebe a sua importância em termos da institucionalização e é importante destacar que seu trabalho não se restringe às obrigações eventuais dentro da própria universidade, mas se estende para outras frentes como a publicação de obras de importantes "geógrafos físicos”, entre outros esforços, inclusive o da publicação de livro didático (um estudo regional sobre a Alemanha) que, editado em 1898, permaneceu em uso por muitos anos segundo Moraes (1990).

A contribuição de Ratzel dá-se à frente das pesquisas por ele desenvolvidas e também na divisão em subcampos proposta para a disciplina: Biogeografia, Antropogeografia, Geografia Física. Essa subdivisão, afeta o curriculum dos cursos até os dias de hoje demonstrando a força das proposições do autor na estruturação dos cursos de Geografia. Segundo Moraes,

Internamente, Ratzel dividiu a geografia em três grandes campos de pesquisa: a geografia física, a biogeografia e a antropogeografia. Estas três vertentes da ciência geográfica foram concebidas como estudos sintéticos (que buscam relações entre fenômenos diversificados) e explicativos (capazes de gerar leis), que, por sua vez, subdividir-se-iam em variadas geografias especiais - tópicas e descritivas. (MORAES, 1990, P.9)

Dessa forma, a Antropogeografia para o autor estaria dividida ainda em três frentes de estudos: a) influência que os fatores naturais exercem sobre as sociedades humanas; b) estudo da distribuição dos povos e sua difusão sobre o espaço; c) estudo 
da formação dos territórios. Esta subdivisão das frentes de estudo e pesquisa nos remetem à organização da Geografia conforme praticada ainda hoje e que aparecem nas grades curriculares dos cursos despertando fortemente nossa atenção. A Geografia Humana tal qual a executamos, mas também a Geografia da População e Migrações e a Geografia Política são componentes curriculares obrigatórios na maioria absoluta de nossos cursos de graduação e se desdobram em temas de pesquisa também em nossas pós-graduações demonstrando a legitimidade ou a eficácia política alcançada pelas proposições ratzelianas.

Mesmo a Geografia Política que experimentou tão fortes críticas pelos geógrafos franceses sobretudo, não deixou de ser praticada ou ensinada. A partir dos anos de 1980, volta com força renovada às grades curriculares dos cursos e ganha cada vez maior força nas últimas décadas.

É importante lembrar que, a despeito da proposição do conceito de região aparecer nas elaborações de Vidal de La Blache como uma categoria de caráter neutro, ou seja, objetivo e sem envolvimento com as questões do Estado, foi fortemente influenciado pelo eco que a retomada da Alsácia e da Lorena pelos germânicos em 1871, causou na academia. Yves Lacoste foi o primeiro geógrafo a trazer à luz o livro France de Leste do pioneiro La Blache em que a posição estratégica da região da Alsácia e da Lorena é mostrada em toda sua importância para a França (CAMPOS, 2014; RIBEIRO, G., 2011). Como desdobramento, surge um dos principais eixos de dedicação dos geógrafos, qual seja a Geografia Econômica de cujos temas tantos subeixos foram desenvolvidos como a Geografia do Comércio, da Indústria, dos Transportes etc, mas também, como decorrência da interligação com o fenômeno do crescimento das cidades, a própria Geografia Urbana.

\section{CONSIDERAÇÕES FINAIS}

Segundo Jörn Seemann (2012, p.3) “... Ratzel não pode ser dissociado do determinismo ambiental e do imperialismo bismarckiano”, entretanto, não há como negar também a imensa contribuição do autor para a fundação da Geografia Moderna tanto em termos de sua sistematização o que se apresenta com força nas inúmeras obras de sua autoria. Suas contribuições teórico-metodológicas foram extremamente bem-sucedidas, para a satisfação de alguns e para irritação de outros. 
Quanto à institucionalização Ratzel alcançou a eficácia política necessária e colocou a Geografia entre as disciplinas científicas clássicas e assim ela tem permanecido bravamente em meio às críticas severas das diversas frentes, sejam as provindas das ciências coirmãs como a história e, principalmente a sociologia, mas também de frentes mais distantes em sua eterna dúvida sobre a viabilidade das ciências humanas.

Evidentemente, toda a disciplina foi sendo ressignificada em sua estrutura e método e merece discussão mais aprofundada o que não cabe nos limites deste texto. Vale, porém, a menção à necessidade de uma maior e melhor explicitação do desenvolvimento institucional da Geografia e, inclusive, na eficácia política que a disciplina científica tem alcançado ao longo do processo histórico.

Da mesma forma, cabe pensar sobre o papel que a universidade de forma geral assumiu como "condutora" do pensamento, como centro de conhecimento e de poder. Na medida que se sabe que através dela perpetuou-se a retenção do saber somente para os "esclarecidos" e aptos a dominar o conhecimento e o andamento do mundo.

\section{REFERÊNCIAS}

BARBOSA, T. Estética romântica germânica e a paisagem em Humboldt. Percurso da Geografia. Presidente Prudente: UNESP, 2011. (Tese de Doutoramento) BRANDÃO, A.R.P. A postura do positivismo com relação às ciências humanas. Theoria. Revista Eletrônica de Filosofia. V.3, N.6, 2011. Disponível em: <https://www.theoria.com.br/edicaoo611/a_postura_do_positivismo.pdf >. Acesso em: 02/12/2018.

CAMPOS, R.R. Breve análise de “A França de Leste”, de Vidal de La Blache. Geo UERJ. Rio de Janeiro, A.16, N.25, V.2, 2014, pp.172-208. Disponível em: <http://www.epublicacoes.uerj.br/index.php/geouerj> Acesso em: 20/03/2018.

CAPEL, H. Institucionalizacion de la Geografiay estrategias de la comunidad cientifica de los geografos. Geocrítica. Cuadernos Críticos de Geografia Humana. A.1, N.8, mar.1977. Disponível em: <www.ub.edu/geocrit/geo8.htm>. Acesso em: 24/o3/2018. GOLDMANN, L. Dialética e Cultura. Rio de Janeiro: Paz e Terra, 1967.

LACOSTE, Y. A Geografia isso serve, em primeiro lugar, para fazer a Guerra. $17^{\mathrm{a}}$.ed. São Paulo: Papirus Ed., 2020. (8ª . Reimpressão). 
LATOUR, B. Ciência em ação: como seguir cientistas e engenheiros sociedade afora. São Paulo: UNESP, 2000.

MACHADO, L.O. Origens do pensamento geográfico no Brasil: meio tropical, espaços vazios e a ideia da ordem (1870-1930). In: CASTRO, I.E.; GOMES, P.C.C.; Corrêa, R.L. (Orgs). Geografia: Conceitos e temas. Rio de Janeiro: Bertrand Brasil, 1995. MORAES, A.C.R. Ratzel. São Paulo: Ed. Ática, 1990.

MORAES, A.C.R.; COSTA, W. M. Geografia Crítica: a Valorização do Espaço. $4^{\mathrm{a}}$. ed. São Paulo: Hucitec, 1999.

RATZEL, F. Evolução dos conceitos relativos à influência que as condições naturais exercem sobre a humanidade. In: MORAES, A.C.R. Ratzel. São Paulo: Ed. Ática, 1990. Pp.32-53

RIBEIRO, G. A Geografia e o desafio da modernidade: La France de L'Est (LorraineAlsace) cem anos depois. Biblio 3W. Rev. Bibliográfica de Geografía y Ciencias Sociales. V.XVI, N.934, jul. 2011 [Serie documental de Geo Crítica. Cuadernos Críticos de Geografía Humana]. Disponível em: < www.ub.edu/geocrit/b3w-934.htm>. Acesso em: 20/03/2018.

SEEMANN, J. Terra Brasilis (Nova Série). Revista da Rede Brasileira de História da Geografia e Geografia Histórica. V.1, N.1, 2012. Pp. 1-16. Disponível em:

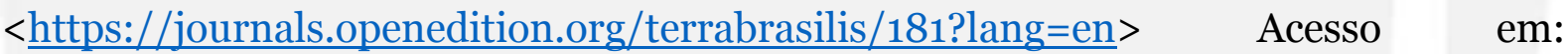
$10 / 02 / 2018$ 